Editorial

\title{
Bionics: human organ and hope
}

\section{Editorial}

Bionics is an important applied biomedical engineering field. It is an important useful science. The application of bionics for construction of artificial organ has been a hope in medicine for a long time and becomes the reality at present. Bionics engineers can use combination of several sciences including material science, minielectronics and megacomputers, advanced robotic mechanisms, rehabilitation medicine and computational algorithms in construction of the artificial organ. ${ }^{1}$ The main application is usually in prosthesis construction. ${ }^{2}$ This is not the concept of regeneration medicine but it is the functional restoration medicine. ${ }^{3}$

As proposed by Merolli, "Probably, "can we regrow a human arm?" is not the right question. Instead, we should ask, "can we restore the function of a lost human arm?'3 The clinical evaluation on the efficacy and effectiveness of the new developed bionic tool becomes the important consideration at present. The issue on the investment for bionic research is widely discussed and most agree with the usefulness of bionic research. ${ }^{4}$ However, there are still many limitations of the bionics research in the present day. At present, the bionics researching is restricted to few countries. The lack of the expert in the field is usually the main problem. As a multidisciplinary science, it might be difficult for the practitioner to understand but it is the important knowledge to be recognized.

\section{Acknowledgments}

None.
Volume 2 Issue 6 - 2018

Viroj Wiwanitkit
DY Patil University, India

Correspondence: Viroj Wiwanitkit, Honorary professor, Dr DY Patil University, Pune, India, Email wvivoj@yahoo.com

Received: November 26, 2018 | Published: December 07, 2018

\section{Conflicts of interest}

None.

\section{References}

1. Craelius W. The bionic man: restoring mobility. Science. 2002;295(5557):1018-1021.

2. Pylatiuk C, Döderlein L. Bionic arm prostheses. State of the art in research and development. Orthopade. 2006;35(11):1169-1170.

3. Merolli A. Can we regrow a human arm? A negative perspective from an upper-limb surgeon. J Mater Sci Mater Med. 2013;24(11):2635-2638.

4. Engelberts CE, Mevius L. The white coat as a cape: doctors, superheroes and bionics. Ned Tijdschr Geneeskd. 2013;157(51):A7218. 